\section{Aerial and Terrestrial Photogrammetric Point Cloud Fusion for Intensive Forest Monitoring}

Gl_Forum 2019, Issue 2

Page: 60 - 72

Shortl Paper

Corresponding Author:

stuart.krause@thuenen.de

DOI: 10.1553/giscience2019_02_s60

\author{
Stuart Krause 1,2,3 \\ 'Thünen Institute of Forest Ecosystems, Germany \\ 2Eberswalde University of Sustainable Development, Germany \\ 3University of Bonn, Germany
}

\begin{abstract}
Remote sensing methods for forest monitoring are evolving rapidly thanks to recent advances in Unmanned Aerial Vehicle technology and digital photogrammetry. Photogrammetric point clouds allow the non-destructive derivation of individual tree parameters at a low cost. The fusion of aerial and terrestrial photogrammetry for creating full-tree point clouds is of utility for forest research, as tree volume could be assessed more economically and efficiently than by traditional methods. However, this is challenging to implement due to difficulties with co-registration and issues of occlusion. This study explores the possibility of using spherical targets typically used for Terrestrial Laser Scanning to accomplish the co-registration of UAV-based and terrestrial photogrammetric datasets. Results show a full-tree point cloud derived from UAV oblique imagery in combination with terrestrial imagery. Despite issues of noise produced from the sky in terrestrial imagery, the methodology is promising for aerial and terrestrial point cloud fusion.
\end{abstract}

\title{
Keywords:
}

point cloud fusion, UAV, terrestrial imagery, photogrammetry

\section{Introduction}

Recent technological developments in remote sensing and photogrammetry have opened up new possibilities for forest monitoring. Thanks to recent developments with consumer-grade sensors, civilian Unmanned Aerial Vehicles (UAVs) and Structure from Motion (SfM) processing software, the acquisition of high-quality spatial and temporal digital information of forests has become possible as well as affordable (Grenzdörffer, Engel, \& Teichert, 2008). UAV-based photogrammetric point clouds have proven successful in estimating various tree parameters such as height and crown diameter (Panagiotidis, Abdollahnejad, Surový, \& Chiteculo, 2016; St-Onge, Audet, \& Bégin, 2015), at the stand and individual tree levels. Terrestrial photogrammetry has also shown success in the extraction of the diameter at breast height (DBH) of individual trees (Piermattei et al., 2019). The empirical derivation of full-tree volumes, however, would require the capture of imagery of the full-tree stem as well as tree crowns. Such image-based point clouds encompassing full trees would require the fusion of 
aerial and terrestrial point clouds. The creation of full-tree point clouds of forest stands has to the authors knowledge only been accomplished using Light Detection and Ranging (LiDAR) technology (Paris, Kelbe, van Aardt, \& Bruzzone, 2017). Although one study did successfully accomplish the fusion of aerial and terrestrial photogrammetry in a forested area, only the lower portion of tree stems and upper canopy were able to be fused (Mikita, Janata, \& Surový, 2016). Due to matters of occlusion and co-registration, the fusion of aerial and terrestrial photogrammetric point clouds of forested areas depicting full trees has up until now been a challenge.

In this study, the possibility of fusing aerial and terrestrial image-based point clouds of an intensive-monitoring forest stand will be explored. An experiment involving spherical 3D targets (Brazeal, 2013) to co-register low oblique UAV-based imagery with terrestrial imagery will be presented. The results are subjected to a quantitative analysis of the horizontal accuracy of extracted tree positions as well as a qualitative analysis of the merged point cloud.

\section{Materials and Methods}

\subsection{Study Area}

The study area is located at the Britz Research Station, approximately $50 \mathrm{~km}$ north-east of Berlin, Germany, near the village of Britz. The plot chosen for the study was a 0.24 ha monoculture stand of Scots Pine (Pinus sylvestris) established in the mid-1970s. The stand consisted of 286 trees which had an average height of $17.5 \mathrm{~m}$. The understorey is comprised of young European Beech (Fagus sylvatica) and Sessile Oak (Quercus petraea) sparsely dispersed throughout the stand. More information about the Britz research station can be found in Krause, Sanders, Mund, \& Greve, 2019; and Krause, Strer, Mund, \& Sanders, 2019.

\subsection{Spherical Ground Control Points}

The aims of spherical ground control points (SGCPs) are to enable the georeferencing of terrestrial imagery as well as to provide a basis for merging terrestrial and aerial imagery. For this experiment, the SGCPs were created by painting a pattern similar to the one that is typically implemented on a 2D Ground Control Point (GCP) on to low-cost Styrofoam spheres mounted on poles. Five target points (North, South, East, West and 'top') were measured and painted on the spheres using black acrylic paint. Terrestrial imagery makes use of the four azimuth directions; the 'top' target would be visible in aerial nadir and oblique imagery, depending on gaps in the forest canopy.

The GCPs and tree positions were measured using a Total Station (Sokkia ${ }^{\circledR}$ Set 510) (TS) from a known absolute position and marked permanently with the installation of PVC pipes buried vertically into the ground. During the field campaign, the poles with the mounted SGCPs were placed inside the PVC pipes, which were positioned perpendicular to the ground using a spirit level (see Figure 1a, 1b). The height from the ground GCP to the base of the sphere was measured (approx. $1.6 \mathrm{~m}$ ) and the targets lined up to magnetic north with a compass. Aerial and terrestrial imagery was acquired on the same day to enable the same SGCP positioning for both acquisitions. 

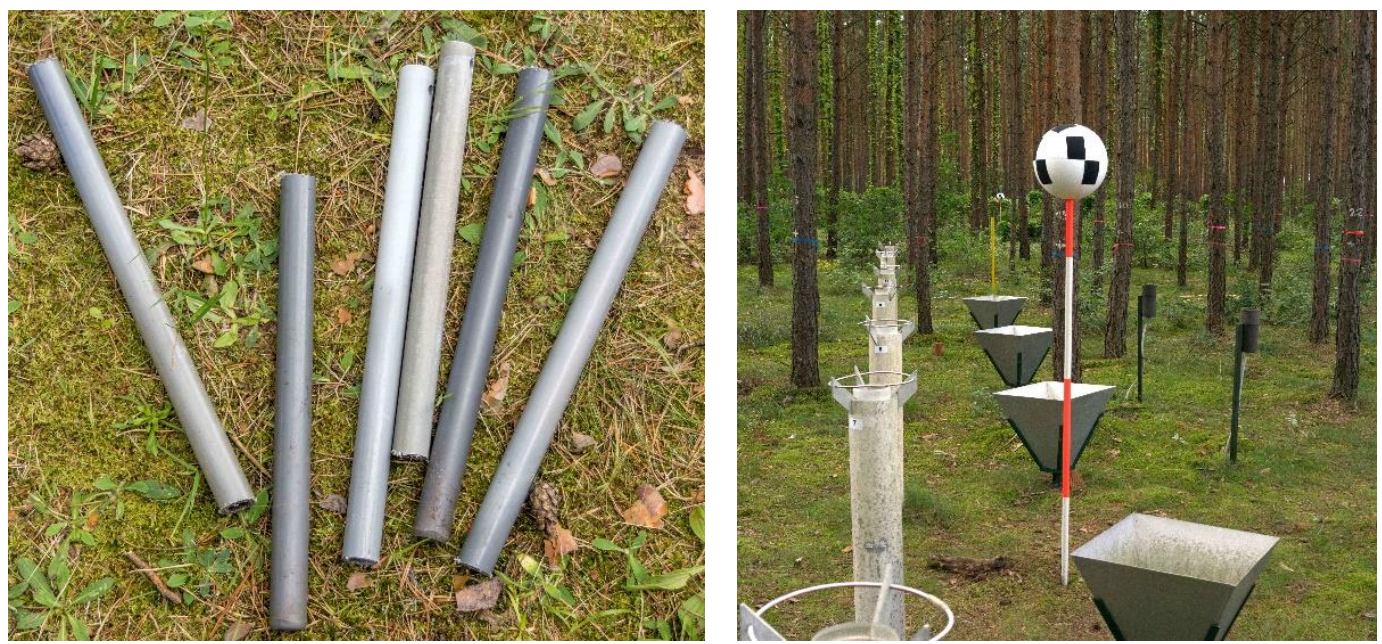

Figure 1: (a) PVC Piping installed at each ground control point; (b) the spherical ground control point after levelling

In order to calculate the geolocations of the four azimuths, the middle of the sphere was calculated by adding the radius of the sphere to the base height. From the middle of the sphere, the four targets were calculated using the radius $(0.153 \mathrm{~m})$ and each cardinal direction angle. The 'top' target of the sphere is the same as the ground GCP in terms of X and Y coordinates; the $\mathrm{Z}$-value is calculated simply by adding $2 \mathrm{r}$ to the base value. The calculation of the sphere's azimuth target points are as follows:

$$
\begin{aligned}
& S G C P_{x}=\sin \left(a \frac{\pi}{180}\right) r+G C P_{x} \\
& S G C P_{y}=\cos \left(a \frac{\pi}{180}\right) r+G C P_{y}
\end{aligned}
$$

where $a=0,90,180$ or $270^{\circ}$, and $r=0.153 \mathrm{~m}$.

\subsection{Aerial Image Acquisition}

The aerial oblique imagery was acquired with a Sony ${ }^{\circledR}$ A $7 \mathrm{r}$ fixed-lens camera ( $35 \mathrm{~mm}$ Zeiss Sonnar 2.8) mounted on an OctoXL 6S12 Octocopter from Mikrokopter ® (HiSystems $\mathrm{GmbH}$ ). The camera was triggered using an intervalometer, set at an angle of $70^{\circ}$, and flown over four separate flight plan grids to ensure 3D coverage (see Figure 2). The flight plans were calculated using the principle of a trapezoid-shaped image ground footprint, where the distance from the bottom of the image footprint to the ground position of the sensor at nadir (Grenzdörffer, Guretzki, \& Friedlander, 2008) is estimated in order to ensure adequate coverage of the forest stand while reducing extraneous imagery outside of the area of interest. Two flight missions were carried out at the end of August 2017 (near solar noon), each mission carrying out two flight plans at a time. 


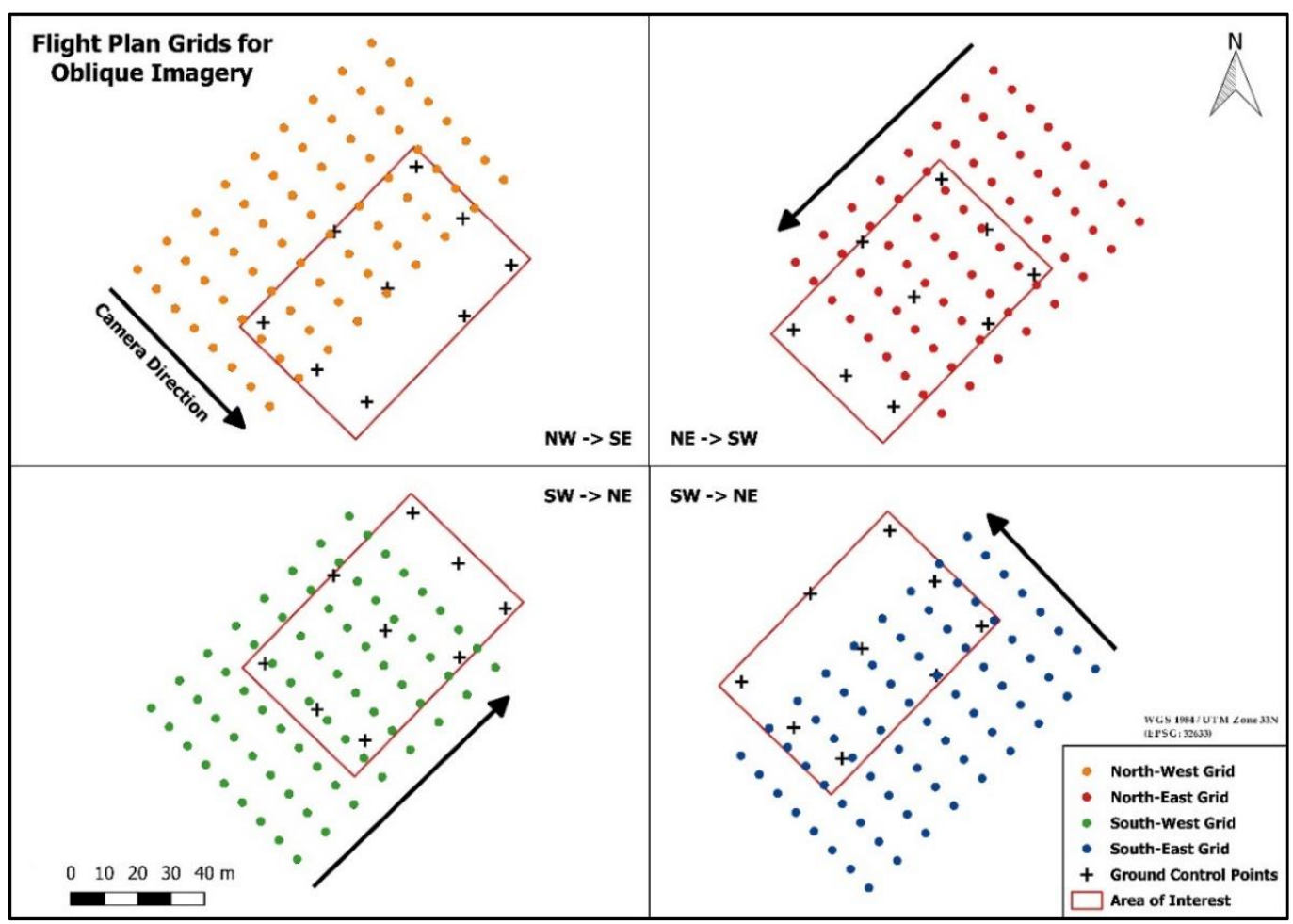

Figure 2: The four flight plan grids used for the acquisition of oblique imagery

\subsection{Terrestrial Image Acquisition}

The terrestrial images were acquired using the same fixed-lens camera as in the UAV campaign. Three images were taken at each camera station in a horizontal fashion, moving from bottom to top. As shown in Figure 3, an outer path surrounding the rectangular forest stand was taken, as well as a path going through the middle of the stand always facing inwards. Additionally, a circle from the centre of the stand facing outwards was carried out at $360^{\circ}$. An attempt was made to take three images at each camera station such that every image contained at least one SGCP (see Figures 4a, 4b, 4c). Ideally, multiple SGCPs were visible within a single image. The terrestrial campaign was carried out directly after the UAV campaign in order to reduce the effects of varying solar illumination. 


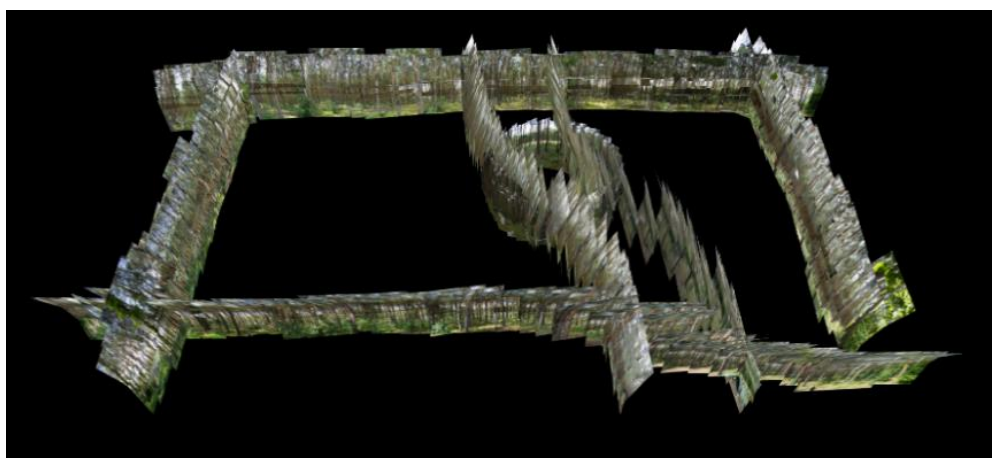

Figure 3: Terrestrial image acquisition path

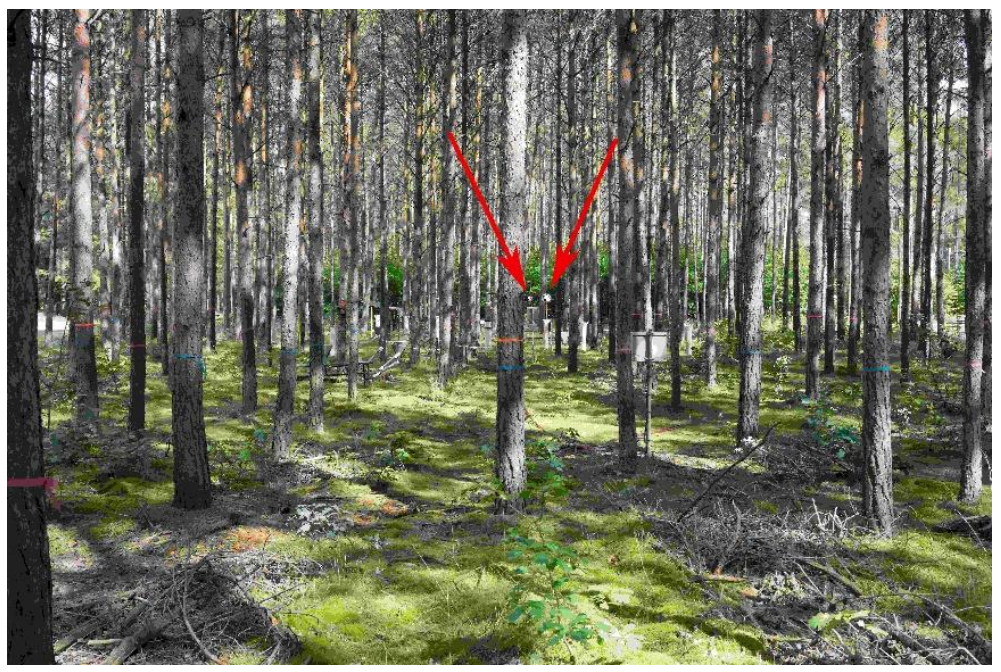

(a)

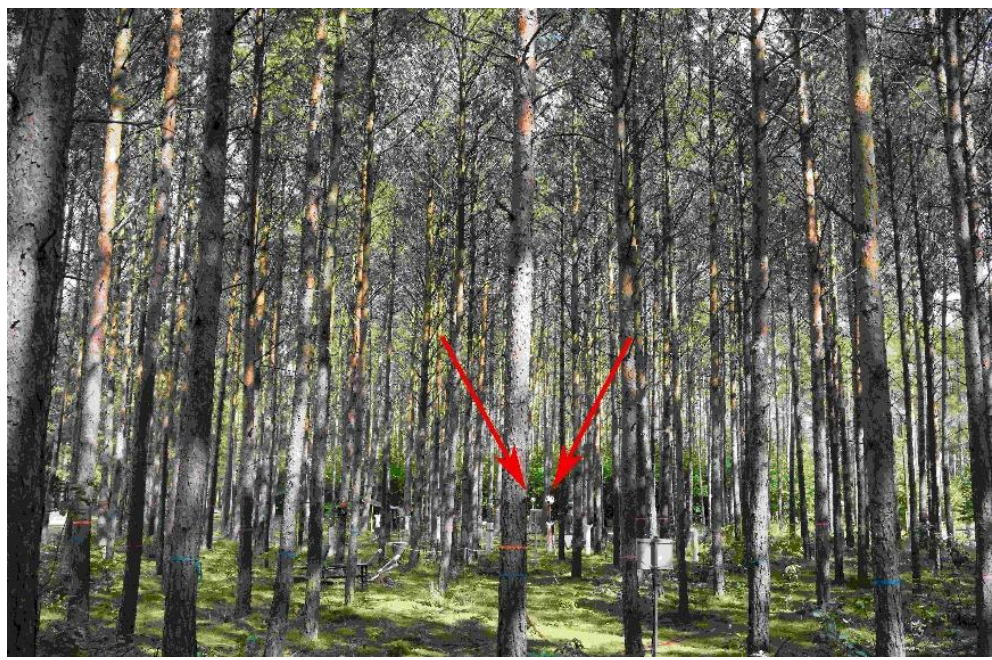

(b) 


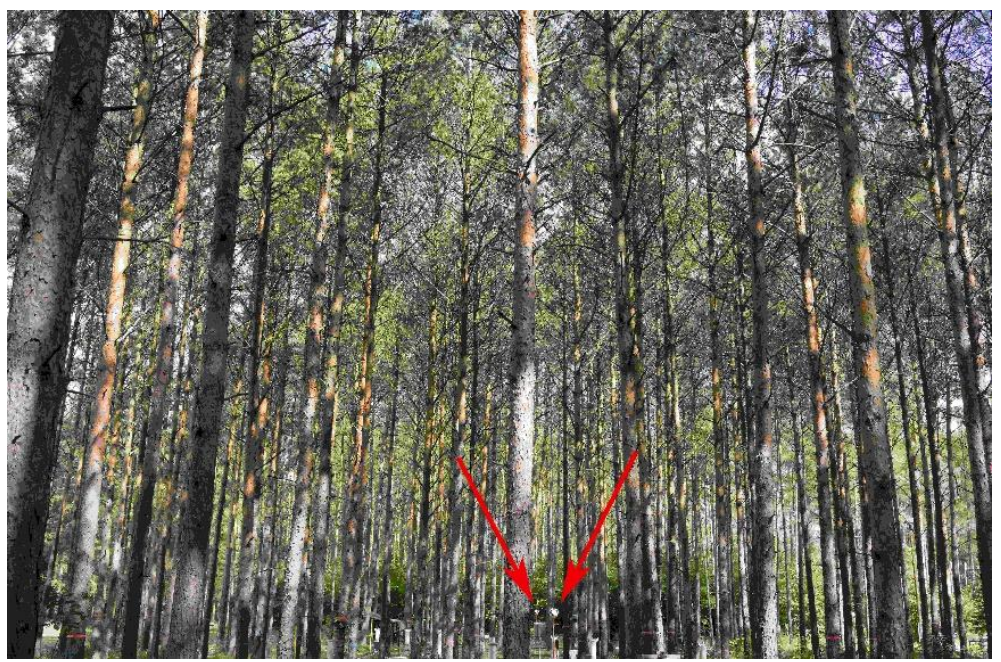

(c)

Figure 4: Terrestrial imagery: (a) first image with $60 \%$ ground; (b) second image with $20 \%$ ground; (c) third image with $0 \%$ ground. Red arrows point to the position of the same spherical target in all three images (a, b and c)

\subsection{Processing}

Images from both campaigns were adjusted for exposure and converted to 8-bit TIFF. The

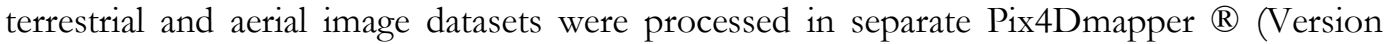
$4.1 .24,2018)$ projects until the calibration stages. The projects were then merged into one larger project where the full point cloud was processed. Further point cloud editing and analysis were carried out in CloudCompare ${ }^{\circledR}$ (Version 2.9, 2018), as well as lidR (Roussel \& Auty, 2018) and TreeLS (de Conto, 2019) packages in R (R Core Team, 2016). The processing workflow and acquisition of the image datasets and field data are shown in Figure 5. 


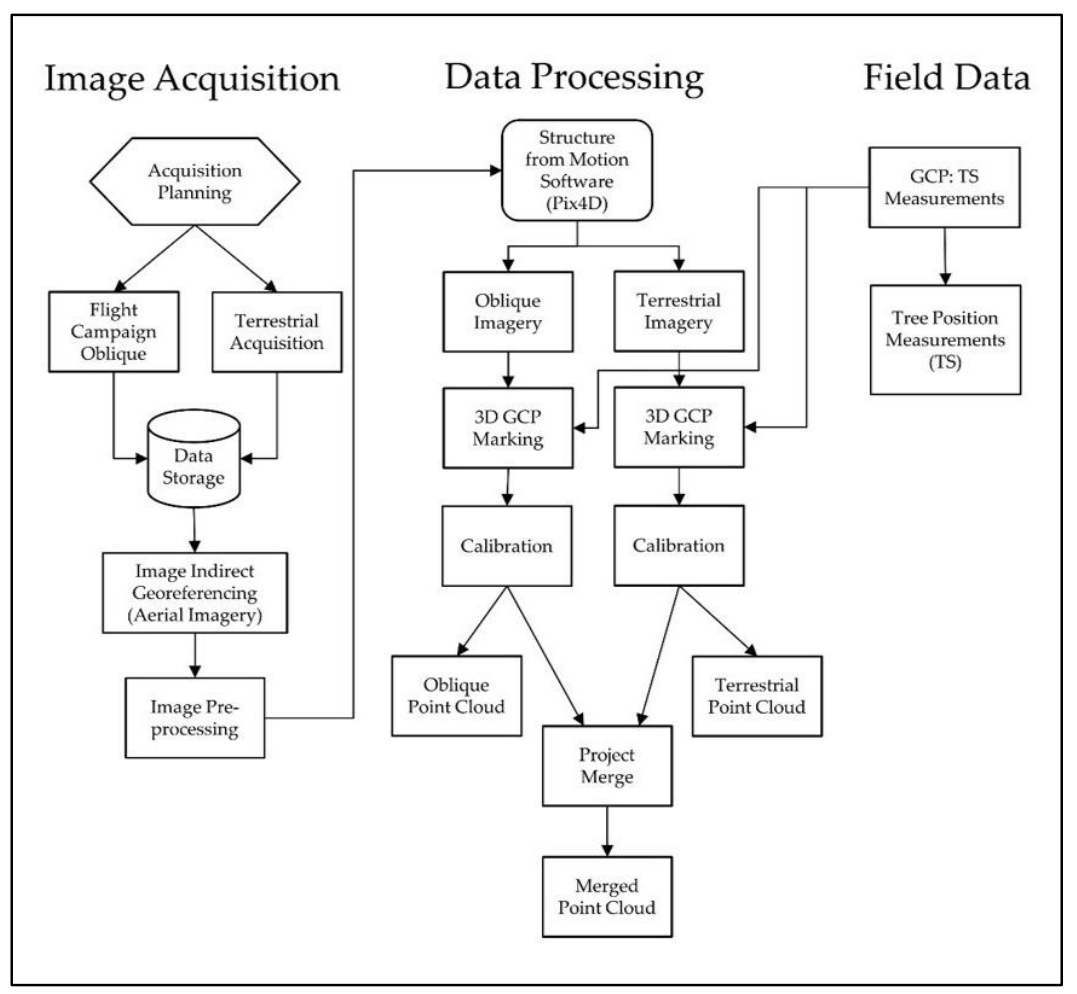

Figure 5: Flowchart showing the image acquisition and processing workflow

\subsection{Statistical Analysis}

The root-mean-square-error (RMSE) established within the Pix4D photogrammetry software gives an estimate of the systematic error (X, Y and Z) within the photogrammetric block with reference to the marked SGCPs.

The estimated tree positions were extracted as the centroid at the base of each stem and validated for horizontal accuracy (X, Y) against the TS tree position measurements. A quantification of the horizontal error at 95\% confidence level was calculated as follows (McGlone \& Lee, 2013):

$$
\text { Horizontal Accuracy }=2.4477 * 0.5 *\left(R M S E_{X}+R M S E_{Y}\right)
$$

\section{Results}

\subsection{Accuracy Assessment}

The final point cloud was derived from almost 1,000 images and comprised over 85 million points. The reported (Pix4D) RMSE of the merged project was estimated at $0.063 \mathrm{~m} ; 29$ SGCPs were utilized throughout the whole photogrammetric block. Table 1 gives an overview 
of the results of the photogrammetric processing. The level of error in the terrestrial dataset $(\mathrm{RMSE}=0.073 \mathrm{~m})$ in comparison to the aerial dataset could be due to the increased number of SGCPs implemented.

Table 1: Results of the photogrammetric processing

\begin{tabular}{llllll}
\hline Project & Images & RMSE $(\mathrm{m})$ & SGCPs & Point Count & $\begin{array}{l}\text { Point Density } \\
\left(\mathrm{m}^{3}\right)\end{array}$ \\
\hline UAV-based & 378 & 0.014 & 9 & - & - \\
Terrestrial & 614 & 0.073 & 20 & - & - \\
Merged & 992 & 0.063 & 29 & $85,219,047$ & $6,898.16$ \\
\hline
\end{tabular}

In terms of horizontal error, the extracted tree positions $(n=270)$ were estimated at $0.69 \mathrm{~m}$ when validated against the TS tree position measurements at a $95 \%$ confidence level. In other words, $95 \%$ of the 270 photogrammetrically derived tree-stem positions will have an error equal to or less than $0.69 \mathrm{~m}$ with respect to the TS measurements. Figure 6 shows the extracted tree positions from the fused point cloud in relation to the TS measured tree positions. From the 286 actual trees, 16 trees remained undetected - a detection rate of $94.41 \%$. Increased horizontal accuracy as well as detection rate are evident in the central part of the area of interest (see Figure 6).

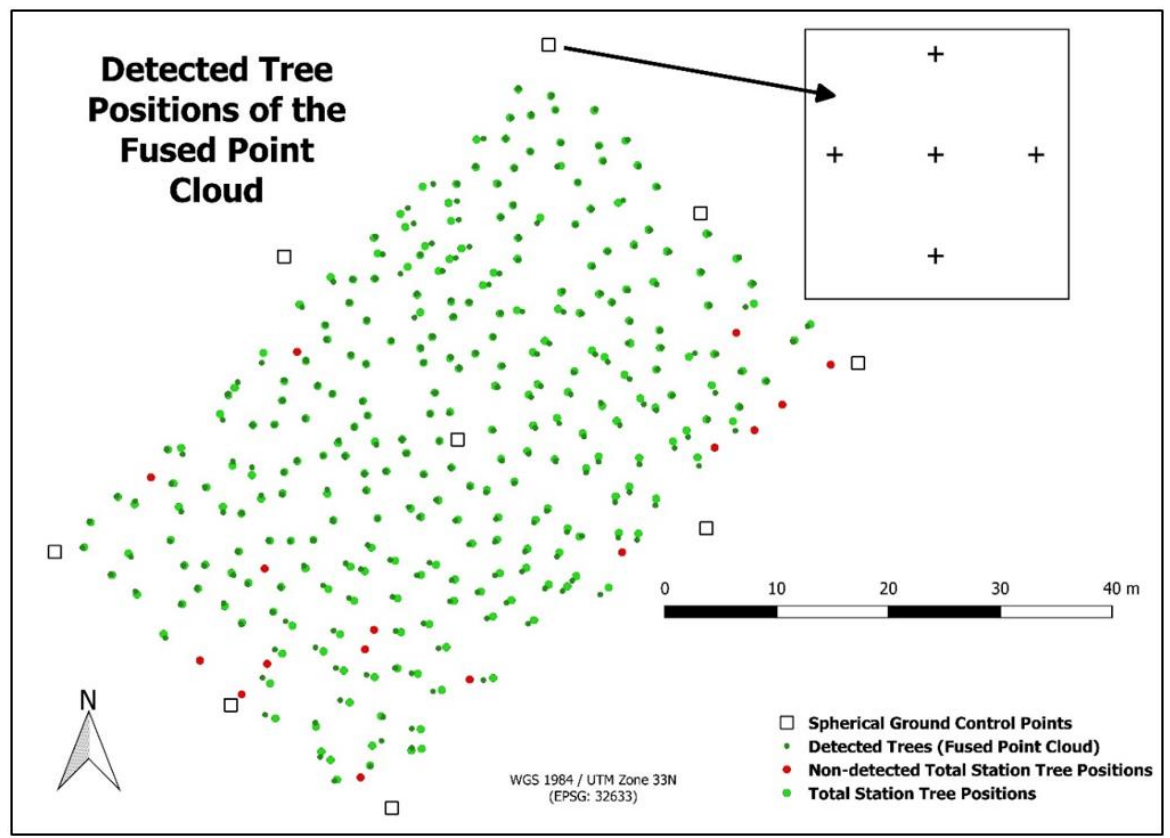

Figure 6: Detected tree positions in the point cloud shown in comparison to the Total Station tree position measurements. The crosshairs shown in the box in the upper right-hand corner represent the 4 cardinal directions and the top (centre) of a spherical target. 


\subsection{Qualitative Analysis of the Resulting Point Cloud}

For visualization purposes, point clouds were also processed for the oblique and terrestrial datasets separately. Figure 7 shows the variation in coverage for both datasets. A large proportion of the upper and lower tree crowns were reconstructed using the oblique imagery (Figure 7a). The terrestrial imagery was responsible for the reconstruction of the tree stems with added noise due to sky within images (Figure 7b). From the ground view perspective of the RGB point cloud shown in Figure 8, each tree stem is for the most part intact, and artefacts or noise are minimal in the lower parts of the tree stems. In the upper canopy however, noise due to sky in the terrestrial imagery is also evident in the form of white points (see Figure 9).
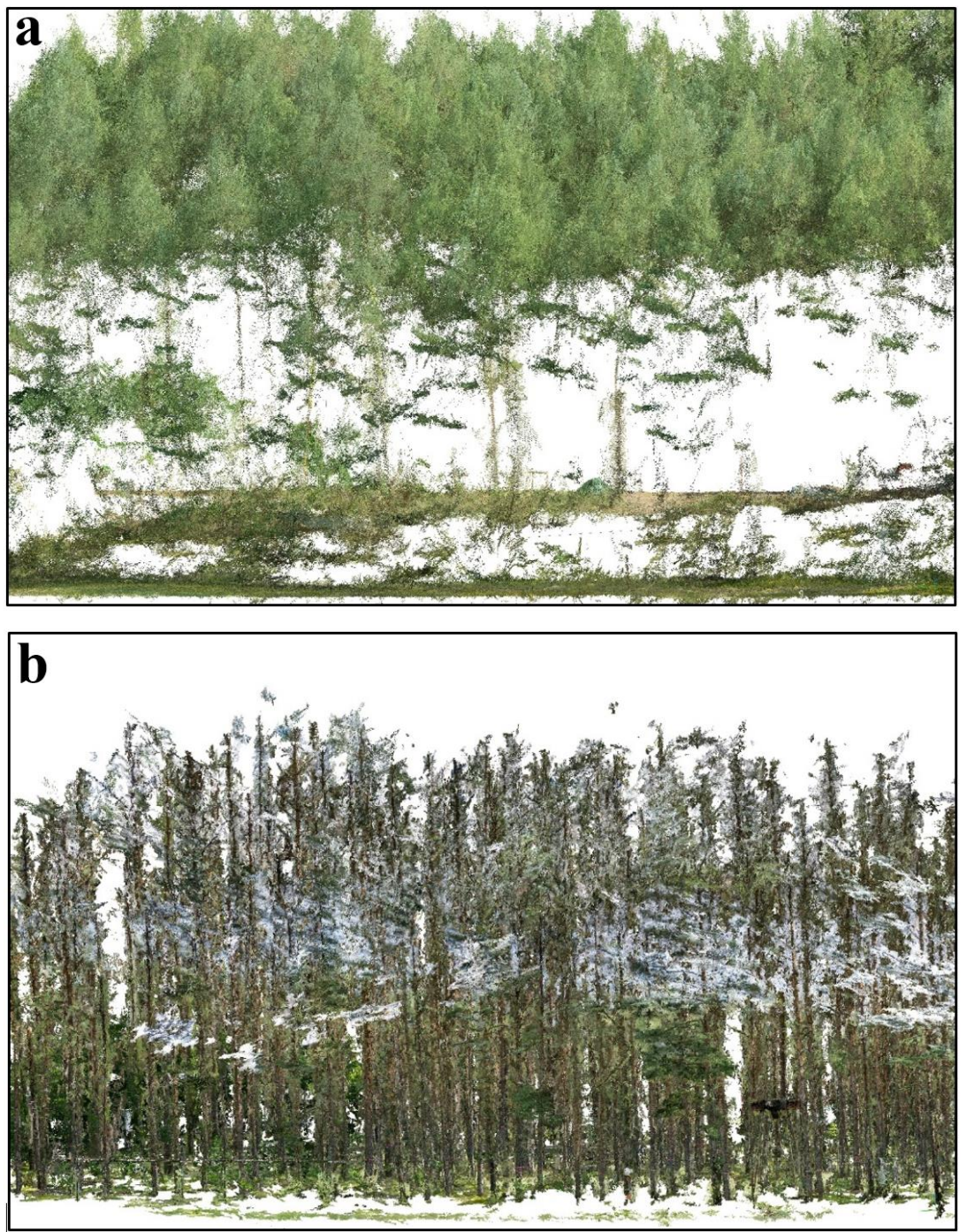

Figure 7: (a) Point cloud derived from oblique imagery; (b) Point cloud derived from terrestrial imagery 


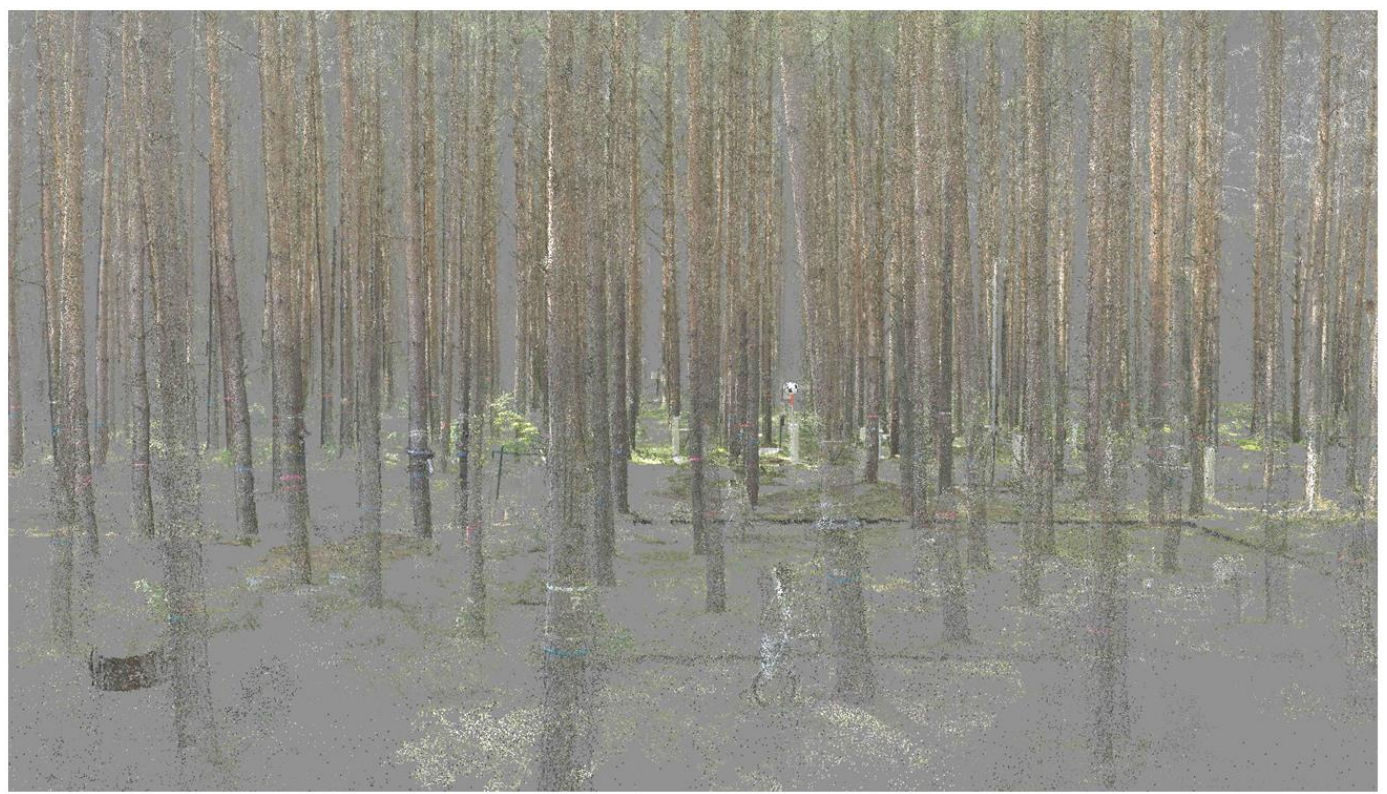

Figure 8: View within the resulting merged point cloud from the ground perspective

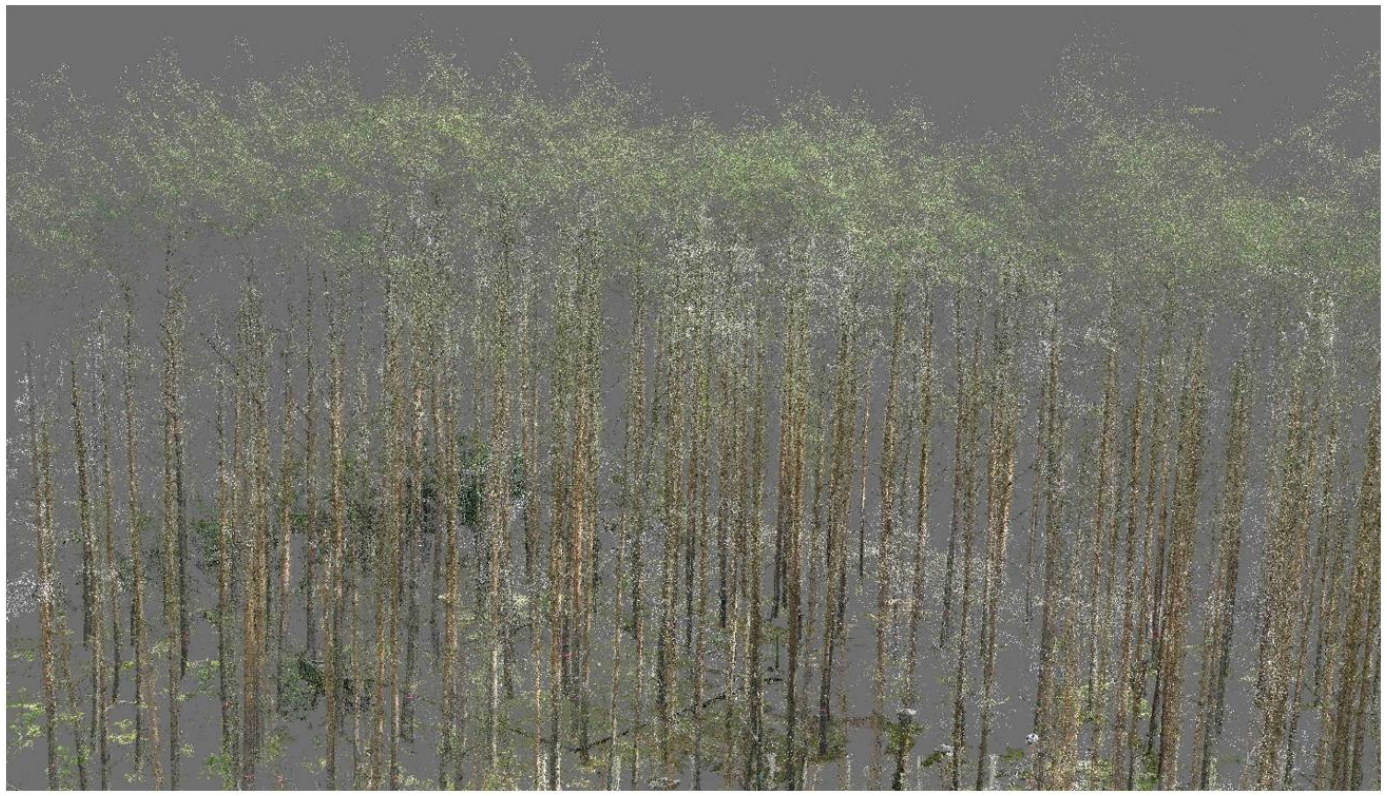

Figure 9: Oblique aerial view of the resulting merged point cloud. White points in the upper canopy are due to noise propagated from sky in the terrestrial imagery

A random tree was chosen and segmented from the point cloud for further analysis. Segmenting the stem within the point cloud at the typical diameter at breast height (DBH) of 
$1.3 \mathrm{~m}$ (see Figure 10, left) shows that it is possible to measure the diameter using, for example, stem-modelling algorithms (de Conto, Olofsson, Görgens, Rodriguez, \& Almeida, 2017). As height increases however, noise in the point cloud becomes more prominent, which could result in stem diameter estimation inaccuracies (see Figure 10, right). The full tree depicted in Figure 10 (right) illustrates the potential to carry out detailed tree crown measurements, despite noise issues. Figure 11 displays the possibility to denoise a segmented saw log by the manual removal of extraneous points, potentially enabling more precise digital measurements.
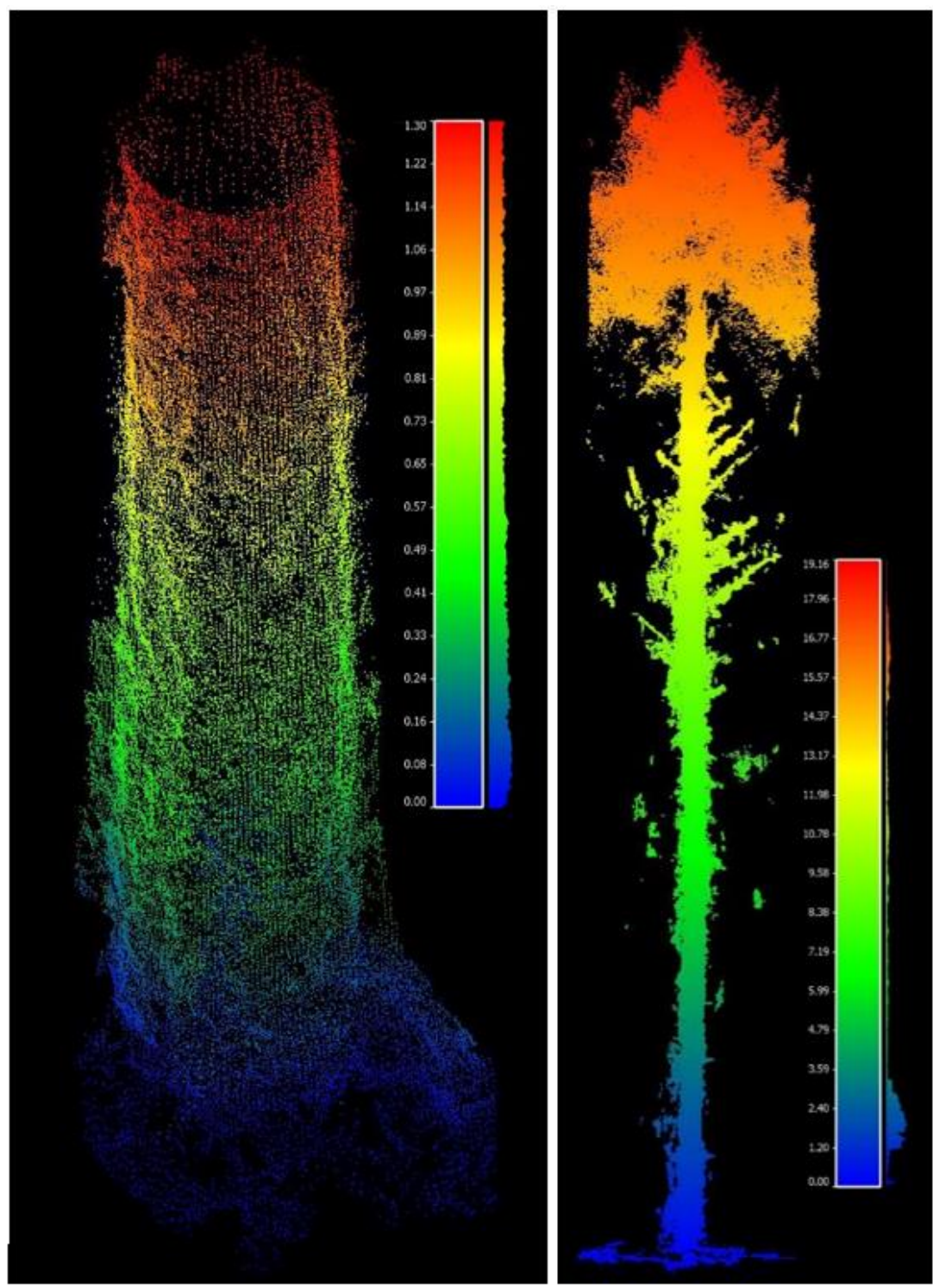

Figure 10: (left) Tree stem segmented at the DBH (1.3 m); (right) Full tree with intact stem and crown. The amount of noise increases with height. Values are shown in metres 


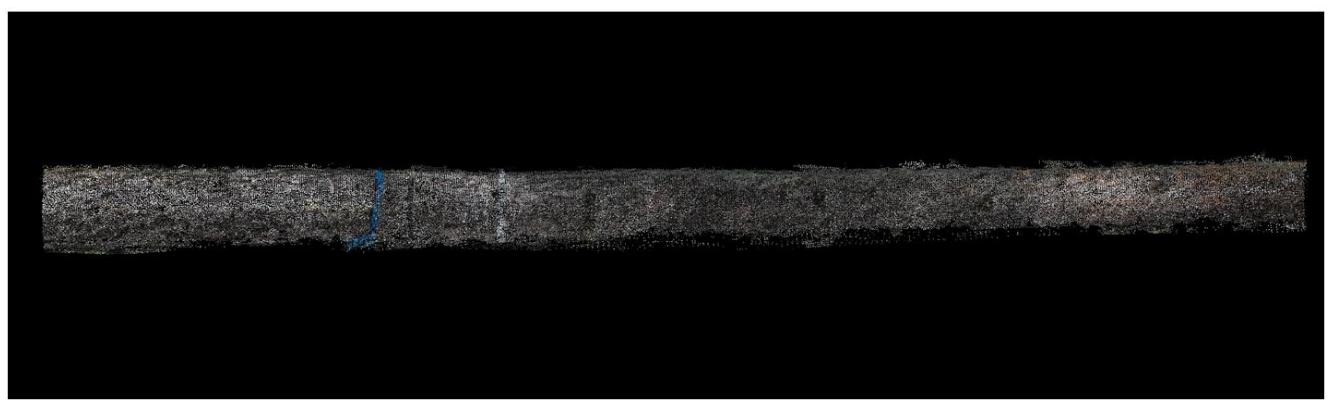

Figure 11: Tree stem (RGB) segmented at $4 \mathrm{~m}$ with the manual removal of extraneous points

\section{Discussion and Future Work}

The approach presented in this study represents a successful attempt at fusing aerial and terrestrial image datasets. Tree positions extracted from the point cloud resulted in a higher horizontal accuracy and detection rate within the central parts of the area of interest (see Figure 6). This shows that when planning the acquisition of terrestrial imagery, a buffer zone outside an area of interest could potentially improve the horizontal accuracy and detection of tree stems near the inner parts of the area of interest. Also evident in Figure 6 is the radial systematic error, which could be due to inaccurate northing of the spherical targets.

Full point clouds of forest stands can be used to derive various forest parameters and could be deemed multi-purpose in terms of their utility, especially if they are acquired at frequent intervals. Despite increased noise in the upper canopy, this methodology could prove competitive to Terrestrial and Airborne Laser Scanning (TLS, ALS) at a lower cost when a permanent GCP installation is available. The benefit of permanent GCPs at intensivemonitoring plots is that they have the potential to be measured with a Total Station, which in turn eliminates the problem typical of mobile field campaigns in terms of RTK GNSS multipath effects under a dense forest canopy. The question remains as to whether it is possible to remove the noise from the point clouds using automatic methods in order to enable reliable diameter measurements to be made throughout entire tree stems.

Further development of the method using spherical targets to co-register aerial and terrestrial imagery as described in this study is merited. Spherical targets manufactured using weatherproof materials conducive to geometric integrity could improve overall accuracy of the photogrammetric block. The next step is to develop automatic methods to denoise artefacts within the photogrammetric point cloud. This would enable more precise stem diameter measurements throughout the whole tree stem. Furthermore, such stem diameter measurements require validation through destructive methods.

\section{Acknowledgements}

This research would not have been possible without the support of Dr. Tanja Sanders and the team at the Britz research station (Thünen Institute of Forest Ecosystems), or Prof. Dr. Jan- 
Peter Mund (Eberswalde University of Sustainable Development) and Prof. Dr. Klaus Greve (University of Bonn).

\section{References}

Brazeal, R. (2013). Low Cost Spherical Registration Targets for Terrestrial Laser Scanning. https://doi.org/10.13140/2.1.4091.0724

de Conto, T. (2019). TreeLS: Terrestrial Point Cloud Processing of Forest Data (Version 1.0). Retrieved from https://CRAN.R-project.org/package=TreeLS

de Conto, T., Olofsson, K., Görgens, E. B., Rodriguez, L. C. E., \& Almeida, G. (2017). Performance of stem denoising and stem modelling algorithms on single tree point clouds from terrestrial laser scanning. Computers and Electronics in Agriculture, 143, 165-176. https://doi.org/10.1016/j.compag.2017.10.019

Grenzdörffer, G. J., Engel, A., \& Teichert, B. (2008). The photogrammetric potential of low-cost UAVs in forestry and agriculture. The International Archives of the Photogrammetry, Remote Sensing and Spatial Information Sciences, 31(B3), 1207-1214.

Grenzdörffer, G. J., Guretzki, M., \& Friedlander, I. (2008). Photogrammetric image acquisition and image analysis of oblique imagery. The Photogrammetric Record, 23(124), 372-386.

Krause, S., Sanders, T. G. M., Mund, J.-P., \& Greve, K. (2019). UAV-Based Photogrammetric Tree Height Measurement for Intensive Forest Monitoring. Remote Sensing, 11(7), 758-. https://doi.org/10.3390/rs11070758

Krause, S., Strer, M., Mund, J.-P., \& Sanders, T. G. (2019). UAV Remote Sensing Data Handling: A Transition from Testing to Long-Term Data Acquisition for Intensive Forest Monitoring. Dreiländertagung Der OVG, DGPF Und SGPF Photogrammetrie - Fernerkundung - Geoinformation - 2019, 28, 8. Vienna, Austria: 39. Wissenschaftlich-Technische Jahrestagung der DGPF e.V.

McGlone, J. C., \& Lee, G. Y. G. (2013). Manual of photogrammetry (6th ed.). Retrieved from http://www.worldcat.org/oclc/856568615

Mikita, T., Janata, P., \& Surový, P. (2016). Forest Stand Inventory Based on Combined Aerial and Terrestrial Close-Range Photogrammetry. Forests, 7(8), 165. https://doi.org/10.3390/f7080165

Panagiotidis, D., Abdollahnejad, A., Surový, P., \& Chiteculo, V. (2016). Determining tree height and crown diameter from high-resolution UAV imagery. International Journal of Remote Sensing, 1-19. https://doi.org/10.1080/01431161.2016.1264028

Paris, C., Kelbe, D., van Aardt, J., \& Bruzzone, L. (2017). A Novel Automatic Method for the Fusion of ALS and TLS LiDAR Data for Robust Assessment of Tree Crown Structure. IEEE Transactions on Geoscience and Remote Sensing, 55, 3679-3693. https://doi.org/10.1109/TGRS.2017.2675963

Piermattei, L., Karel, W., Wang, D., Wieser, M., Mokroš, M., Surový, P., ... Hollaus, M. (2019). Terrestrial Structure from Motion Photogrammetry for Deriving Forest Inventory Data. Remote Sensing, 11(8), 950. https://doi.org/10.3390/rs11080950

R Core Team. (2016). R: A language and environment for statistical computing. Retrieved from http://www.Rproject.org/

Roussel, J.-R., \& Auty, D. (2018). LidR: Airborne LiDAR Data Manipulation and Visualization for Forestry Applications (Version R package version 1.4.1). Retrieved from https://CRAN.Rproject.org $/$ package $=$ lidR

St-Onge, B., Audet, F.-A., \& Bégin, J. (2015). Characterizing the Height Structure and Composition of a Boreal Forest Using an Individual Tree Crown Approach Applied to Photogrammetric Point Clouds. Forests, 6(11), 3899-3922. https://doi.org/10.3390/f6113899 